\title{
La Música en Juan Ramón Jiménez: Una aproximación al Platero y yo de Mario Castelnuovo-Tedesco
}

\section{The Music in Juan Ramón Jiménez: An Approach to Platero y yo de Mario Castelnuovo-Tedesco}

\author{
Silvia Nogales Barrios \\ Universidad de Castilla-La Mancha \\ contacto@silvianogales.com
}

\begin{abstract}
RESUMEN
Juan Ramón Jiménez es una de las figuras esenciales de la literatura española. Entró en la historia gracias a la calidad de sus obras, reconocida con el nobel de literatura en 1956. Debe hacerse una especial mención a su narrativa lírica titulada Platero y yo, una obra universal que ha transcendido la literatura, convirtiéndose en germen de muchas piezas musicales. Entre las obras musicales basadas en el libro juarramoniano, se encuentra el Platero y yo del compositor italiano Mario CastelnuovoTedesco, mereciendo esta composición una especial atención. Este artículo pretende ser una primera aproximación a la figura de Juan Ramón Jiménez desde el ámbito musical, al igual que una introducción a la relación existente entre el Platero y yo de Juan Ramón Jiménez y la obra de Mario Castelnuovo Tedesco para narrador y guitarra que lleva el mismo nombre, mediante el estudio del primer movimiento de la obra.
\end{abstract}

Palabras clave: Castelnuovo-Tedesco, Platero, Juan Ramón Jiménez, música, narrador y guitarra.

\begin{abstract}
Juan Ramón Jiménez is one of the most important figures of Spanish literature, which entered the history for the quality of his works and the nobel prize in 1956. Special mention must be made of his lyrical narrative Platero $y$ yo. This universal work has transcended literature, becoming the inspiration of many musical works, for example the Platero and I of the Italian composer Mario Castelnuovo-Tedesco, which deserves special attention.

This study is a first approach to the connections between Juan Ramón Jiménez and the music, the book Platero y yo by Juan Ramón Jiménez, and the work of the same name for guitar and narrator, written by the composer Mario Castelnuovo-Tedesco.
\end{abstract}

Key words: Castelnuovo-Tedesco, Platero, Juan Ramón Jiménez, music, speech and guitar. 


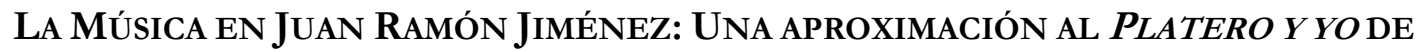 MaRio CASTELNUOVO-TEDESCO}

Nogales Barrios, S. (2018). La Música en Juan Ramón Jiménez: Una aproximación al Platero y yo de Mario Castelnuovo-Tedesco. Cuadernos de Investigación Musical, 4, 54-79. doi: http://dx.doi.org/10.18239/invesmusic.v0i4.1816

\section{INTRODUCCIÓN}

Juan Ramón Jiménez es una de las figuras esenciales de la poesía española y de la poesía contemporánea occidental. Tras la muerte de Rubén Darío asume el liderazgo entre los jóvenes poetas de su tiempo, y a la vez se convierte en referencia de las generaciones posteriores. Su forma de escribir cargada de simbología y profundidad conceptual, marcarán un antes y un después en la literatura, siendo reconocido con el premio nobel de literatura en 1956. Juan Ramón Jiménez obtuvo la distinción por el conjunto de su obra, pero se designó como trabajo destacado su narrativa lírica Platero y yo.

La primera publicación de la obra la llevó a cabo, en 1914, la editorial La Lectura, con el título Elegía Andaluza. Esta primera edición constaba de 63 capítulos. Fue algo más tarde, en 1917, cuando la editorial Calleja publicó la edición completa, compuesta por 138 capítulos y bajo el título Platero y yo. En la edición de 1917 se añadieron capítulos como Arotea, el cual sirve de nombre a un movimiento de la obra musical Platero y yo del burgalés Eduardo Sainz de la Maza.

Como podemos saber gracias a la Fundación Zenobia-Juan Ramón Jiménez, la edición de 1914 estaba destinada a formar parte de la colección Biblioteca de la Juventud. A Juan Ramón no le agradó demasiado por estar "descuidada"; tampoco le entusiasmaron las ilustraciones. En primera instancia barajó distintos títulos para ella, como Platero residente, Platero, Primer Platero, Otra vida de Platero, Último Platero.

En cuanto a su género, Platero es difícil de clasificar. Se podría decir que reúne el género lírico y la novela. Algunos lo califican de relato poético de poemas en prosa, y es cierto que puede leerse independientemente cada capítulo; sin embargo, la lectura de todos los capítulos juntos toma sentido para constituir una obra unificada. El autor Gilbert Azam (1983: 93) señala que el lirismo en Platero y yo impregna cada relato de la obra, lo que ayuda a la fusión de unos con otros. Además, Juan Ramón lo utiliza para expresar las emociones y sentimientos más íntimos y profundos².

Según nos revela el director de la Fundación Zenobia-Juan Ramón Jiménez, Antonio Ramírez Almansa, recogido en un artículo del diario El País, Platero y Yo

\footnotetext{
${ }^{1}$ http:/ / fundacion-jri.es/platero-y-yo/platero/

2 Para saber más acerca del lirismo y estilo de Juan Ramón se recomienda el ensayo de Gicoyate (1971) y que podemos encontrar en la página web del Centro Virtual Instituto Cervantes (Gicovate, 1983). CVC Cervantes. Recuperado de https://cvc.cervantes.es/literatura/aih/pdf/04/aih 041 065.pdf . También puede resultar interesante el libro de Gicovate (1973).
} 


\section{SILVIA NOGALES BARRIOS}

supone el comienzo de la luz y el color en la literatura. Con ella se pone fin a los negros de Goya, a los grises de Zuloaga y comienza una nueva configuración que va a inspirar luego a las Generaciones del 14 y del 27 y, en definitiva, a la poesía absolutamente intemporal que ofrece la prosa lírica de Juan Ramón Jiménez ${ }^{3}$.

Como podemos observar, la obra Platero y yo ha supuesto un hito en la literatura, y una fuente de inspiración para el arte, transcendiendo así al mundo de las letras y llegando a la parcela musical. Si realizamos una acotación del repertorio musical basado en Juan Ramón Jiménez y nos centramos únicamente en el escrito para guitarra, hallamos numerosas obras musicales de notoria importancia inspiradas en Platero y yo. Entre ellas, nos gustaría destacar la obra en cuatro volúmenes del compositor Mario Castelnuovo Tedesco, del cual se cumple en 2018 el cincuenta aniversario de su muerte. Su Platero y yo para narrador y guitarra merece una atención cuidada, ya que se convierte en una de las más extensas e interesantes del repertorio guitarrístico.

\section{LA RELACIÓN DE JUAN RAMÓN JIMÉNEZ CON LA MÚSICA}

\subsection{LA MÚSICA EN SU VIDA}

En la actualidad existen estudios basados en la relación que Juan Ramón Jiménez tuvo con artes como la Pintura ${ }^{4}$, pero no abundan los que ponen el foco en la música.

Sin embargo, se sabe que Juan Ramón Jiménez, desde temprana edad, era un gran melómano. En su etapa adulta, cuando ya se encontraba casado con Zenobia, era un habitual de los conciertos que se organizaban en los teatros Español, María Guerrero y Monumental de Madrid. Durante su exilio en Latinoamérica, también era habitual su presencia en los conciertos ${ }^{5}$. Juan Ramón tenía un carácter introspectivo, y era curiosa su presencia en dichos actos multitudinarios. En los teatros mencionados con anterioridad, actuaban la orquesta Sinfónica y Filarmónica dirigidas por Pérez Casas y Fernández Arbós. Tal y como nos dice Sanz Manzano, el matrimonio estaba abonado al Teatro Real y Juan Ramón fue de los primeros miembros de la Sociedad Nacional de Música.

Antes de adentrarnos en su etapa madrileña, de donde datan sus amistades con grandes músicos y compositores del momento como los pianistas José Cubiles, Ania Dorfmann, Albéniz, Granados, Turina y Falla, nos centraremos en su adolescencia.

\footnotetext{
3 Artículo de periódico online con motivo del 100 aniversario de la primera publicación de Platero y yo, de Intxausti (2014).

${ }^{4}$ Vid, por ejemplo, el trabajo de Crespo (1999). El libro recoge su contacto con la pintura a los 15 años y cómo posteriormente esta visión cambia e influye en su poesía.

${ }^{5}$ Se puede ampliar la información sobre lo anteriormente expuesto en Campoamor (1976: 213) y Jiménez (2014). También gracias a los diarios de Zenobia, podemos encontrar diversas alusiones hacia los Nocturnos, Valses y demás composiciones de Chopin, incluso de otros compositores, que el matrimonio solía escuchar al final de una jornada de trabajo (Camprubí, 2006: 40, 60, 120, 125, 175, 334).
} 


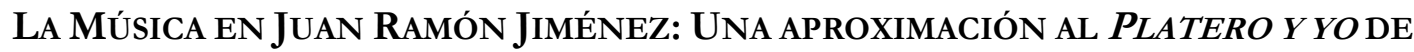 Mario CASTELNUOVO-TEDESCo}

Juan Ramón recuerda que con 15 años sintió vocación hacia la pintura, lo que le hizo desplazarse a Sevilla para estudiar dibujo con Salvador Clemente. Tiempo después encontró su verdadera vocación en la poesía, la cual coparía su vida a partir de ese momento ${ }^{6}$.

En cuanto a la música, no se han encontrado documentos que prueben que Juan Ramón tuviera conocimientos compositivos, aunque expresó en alguna ocasión su deseo o ímpetu de hacerlo ${ }^{7}$. Hay una mención a su faceta interpretativa en su autobiografía Vida, donde nos dice:

No me interesé mucho en la carrera de leyes que mis padres eligieron para mí y abandoné pronto la Universidad de Sevilla donde empecé a estudiarla. A mí me gustaba más pintar, tocar el piano y escribir, y mis padres y toda mi familia, con una compresión y una largueza que nunca agradeceré bastante, decidieron que yo lo hiciera todo a mi gusto (Jiménez, 2014: 103).

Según estas palabras de Juan Ramón, se deja entrever que el escritor sabía tocar el piano. Igualmente encontramos otras declaraciones del nobel que demuestran su afición musical:

Y como todos los niños precoces -ipobres hombrecitos tristes!- tuve un éxito rápido en cuanto hacía. Pintura, música, versos míos eran la admiración de todos, familia y amigos (Jiménez, 2014: 302).

Su faceta melómana propició que en sus obras más tempranas el poeta estableciera una profunda vinculación entre su poesía y la música, vinculación que, por otra parte, como ya nos adelanta Sanz Manzano (1999), pasa desapercibida entre sus estudiosos.

A la edad de 16 años Juan Ramón solía visitar al matrimonio Núñez-Sáenz, los cuales eran familiares. Allí escuchaba obras de Chopin tocadas por Feliciana Sáenz al piano. El

\footnotetext{
${ }^{6}$ En su artículo, Sanz (1999) expresa lo siguiente: "Su mirada de pintor marcó posteriormente su obra literaria, llenándola de color y luz". También encontramos en su autobiografía alusiones a su vocación artística, su etapa en Sevilla e incluso aparece un capítulo entero dedicado a Salvador Clemente. Dicho capitulo es el número VIII y en él le dedica palabras como: "Mi maestro apenas pintaba tampoco- y tenía talento, pero era un fracasado-. Yo, no sé con qué intención, procuraba llevármelo de allí, yo quería que trabajase, que pintase grandes cosas, lo que yo soñaba. Me ponía contento cuando iba a empezar un trabajo, pero lo que hacía siempre era un fracaso ante lo que yo soñaba”. Es posible que Juan Ramón fuera al Ateneo en busca de rigor, el cual no le proporcionaba Salvador Clemente. Muchas cosas relativas a la etapa de pintor las encontramos en Jiménez (2014: 360-367).

7 “Todos los días siento varios ímpetus de pintar y de componer música, y siento que, dentro de mí, el músico y el pintor se van desarrollando al mismo tiempo que el poeta -tres seres distintos- aprendiendo más y más y sin pintar ni componer. Y creo que, de ponerme, en el acto esos progresos serían efectivos. Pero me domino, en la seguridad de que la vida es corta aun para una sola cosa y que se corre el peligro de convertirse en un aficionado general a las artes" (Jiménez, 1990).
} 


\section{SILVIA NOGALES BARRIOS}

poeta admite que las notas musicales que el piano emitía le conseguían embriagar de tal forma que se transportaba a otro mundo ${ }^{8}$.

Por lo tanto, la música se convirtió para él en inspiración para escribir, actuando como un estímulo creador para el poeta.

En su autobiografía titulada Vida, hay un apartado llamado Artes a mí, donde se recoge información sobre la forma que tenía Juan Ramón de concebir el arte. Para él era unidad y su poesía íntima formaba parte de esa unión. Por lo tanto, era deudora de alguna forma de los artistas más admirados por Juan Ramón, los cuales le habían enriquecido su sensibilidad e instruido en el aprendizaje de la música, de los colores, etc. "¿Influencias? Sí, de todas partes. Así, en su incorporación universal de todas se destruirán unas a otras y uno se quedaría libre en más en lo suyo que más entonces"’.

Como se ha expresado anteriormente, Juan Ramón asistía a números conciertos; entre ellos figuran los ofrecidos por sus amigos en Madrid. Estos datos los conocemos gracias a la correspondencia (Jiménez, 2012) que mantuvo el poeta con su madre y amigos, a su autobiografía Vida (Jiménez, 2014: 377), y a distintos libros centrados en él, como el de Palau de Nemes (1974). De su etapa madrileña datan los recitales que ofrecía el matrimonio Martínez-Lejarraga, donde, según Sopeña, se conocieron Falla y Juan Ramón en 1914 ${ }^{10}$.

Otras de sus grandes amistades fueron Pedro García Morales, Oscar Esplá Jiménez, 2012) y el guitarrista Regino Sainz de la Maza. La relación de amistad con este último fue más tardía, y data de la época en la que Juan Ramón Jiménez residía en Puerto Rico. El poeta dijo de él que era "el guitarrista de más vibración poética"11.

Hay más alusiones a esta relación, como por ejemplo la que nos cuenta Ricardo Gullón en su libro El último Juan Ramón Jiménez:

A principios de marzo, el guitarrista Regino Sainz de la Maza acudió a la casa y les ofreció un recital privado. Según Zenobia, “tocó mil veces más sentidamente que en el teatro". Asistieron al concierto público de Regino y días después de Nicanor Zabaleta. Juan Ramón, olvidado de las supuestas molestias cardíacas con que tanto atormentara a Zenobia

\footnotetext{
8 "Esta era la pura verdad, me enloquecía. Los Preludios finales, el 24 sobre todo, sacaban de mi cuerpo, como de una vivienda oscura, el ser más frenético de mi alma incendiada. Loco salía yo de aquella casa a las altas horas de la noche, sin ganas de volver a encerrarme en la mía [...]. A veces, es así, deseaba entrarme corriendo en una amplia muerte por aquel poniente de la noche, lleno de sombras vivas, sonidos lejanos y luminarias fantásticas. La noche, la marisma, el río, el mar, el cielo, y Chopin levantándome con su música las entrañas ideales" (Jiménez, 2014: 227, 228).

${ }^{9}$ En los manuscritos de Vida destinados a esta sección solo se han encontrado listas de músicos de muy diferentes épocas entre ellos: Falla, Albéniz, Debussy, Wagner, Beethoven, Dvorák, Schumman, Schubert, Mendelshon, etc. (Jiménez, 2014: 45, 46).

10 Sopeña (1981: 54-57) Sanz (1999) hablan de María Lejarraga en sus artículos.

${ }^{11}$ Regino Sainz de la Maza se expresaba así en la entrevista al respecto de su relación con Juan Ramón: "Tuve la suerte de tratar bastante a Juan Ramón Jiménez, sobre todo en Puertorrico [sic]. Juan Ramón Jiménez tenía una sensibilidad musical extraordinaria. Yo recuerdo las noches que pasaba en su casa conversando con él, tocando para él y para Zenobia, la cual era una mujer extraordinaria" (Sainz de la Maza, 1979).
}

Cuadernos de Investigación Musical, 2018, junio, nº 4, págs. 54-79.

ISSN: 2530-6847

DOI: http://dx.doi.org/10.18239/invesmusic.v0i4.1816 


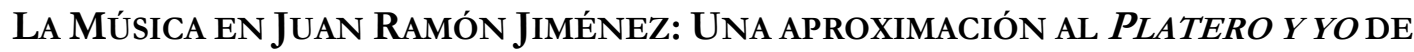 MaRio CASTELNUOVO-TEDESCO}

en Riverdale, subió escaleras en el teatro, y ni pareció reparar en ello. En abril vieron a la bailarina Tere Amorós y Sainz de la Maza volvió a tocar para ellos, en privado ${ }^{12}$.

La relación de amistad entre Falla y Juan Ramón Jiménez merece una mención especial. Son múltiples los libros en los que se trata dicha amistad y la correspondencia mantenida entre el poeta y el compositor. Se podría decir, que esta relación no solo sirvió de enriquecimiento personal, sino que también supuso una influencia en el terreno profesional de los dos artistas.

Es conocido que el Nobel visitaba a Manuel de Falla en su casa granadina e intercambiaban impresiones sobre sus proyectos. Un ejemplo de ello son dos de sus cartas que encontramos en el Epistolario II, publicado por la editorial Residencia de Estudiantes en 2012. La primera de las cartas es reproducida en un artículo titulado Juan Ramón Jiménery Manuel de Falla (Federico Sopeña, 1981). En ella se muestra una gran admiración y un conocimiento superficial de ambos, puesto que el poeta presupone que Falla está casado. La carta la escribe Juan Ramón desde su piso de Conde de Aranda y se puede leer:

Mi querido amigo:

Me dice Sanjuán que piensa usted hacer algo sobre la Luna nueva de Tagore. Le envío los otros libros suyos por si usted no los conoce y en los que encontrará tesoros. Le recomiendo especialmente El cartero del Rey, verdadero raudal de poesía pura. Yo encuentro en Tagore una semejanza de temas, fondos y giros con nuestra única y profunda tierra jesta Andalucía sin fin! Lo que usted hiciera sobre Tagore sería, sin duda, maravilloso. Me gustaría mucho hablar con usted de muchas cosas. ¿Quiere usted venir alguna tarde con su señora a tomar el té con nosotros? Mi mujer tendría un gran placer en conocer a la suya. Como no tenemos día de recibo le agradecerá que nos avise antes si les gusta venir. Su amigo y admirador,

Juan Ramón Jiménez. 1, febrero 1910 Sopeña (1981: 54-57) ${ }^{13}$.

Otra carta, que data del verano de 1920 en Madrid, dice así:

Mi querido amigo:

Cuando me dijo usted la otra noche que no conocía la edición completa de Platero y yo, creí recordar que yo se la había mandado. Me he puesto a buscar entre mis cosas por hacer y enviar, que la exigencia de cada día va amontonando, y me encuentro con unos libros dedicados a usted jen 1917 y 1918! Aunque preparo nuevas ediciones muy variadas de ellos, se los mando, pues son de usted jhace cuatro años! Y con ellos, los otros que di en el mismo año 1917, y Mashi, el último libro que hemos dado de Tagore. Mr. S. muy entusiasmado de

\footnotetext{
12 Estas y otras referencias a dicha amistad aparecen en el libro de Gullón (2006: 126).

13 También podemos encontrarlas en Jiménez (2012: 73-76).
} 


\section{SILVIA NOGALES BARRIOS}

El Retablo. Yo no quise decirle a usted que nos tocara algo de él, la noche que estuvo usted aquí, porque no sabía si le gustaba hacerlo. Pero no me resigno a que se vaya usted a Granada sin oír algo de su nueva obra. ¿Le gustaría venir con su hermana a tomar un refresco con nosotros o preferiría usted, si le es más cómodo, que vayamos nosotros a su casa?

Gracias anticipadas de su verdadero amigo.

J.R.J. (Sopeña, 2012: 163-164) ${ }^{14}$.

Observando la amistad que les unía y basándonos en la actividad profesional entre ambos, no es de extrañar que surgiera la idea de hacer un proyecto conjunto a partir de obras de autores como Góngora, Samain y Chénier.

Hay un dato poco difundido que recoge Sanz (1999), quien nos aporta algo de luz sobre un proyecto conjunto entre Falla y Juan Ramón Jiménez, un frustrado proyecto común de literatura y música basado en la fábula de Polifemo y Galatea ${ }^{15}$. Si se hubiera materializado el proyecto, estaríamos sin duda ante una obra de suma importancia.

También hay constancia de que Juan Ramón Jiménez colaboró o quiso hacerlo con compositores como E. Halffter o Turina ${ }^{16}$.

\section{El Playero y yo de Mario Castelnuovo-Tedesco}

Mario Castelnuovo-Tedesco nace en Florencia y cuenta con antecesores sefarditas de origen español. Desde que era un niño demuestra una gran sensibilidad y dotes para la música, como bien se refleja en Otero (1987: 5). Tedesco fue un compositor excelente que amó la cultura española y las artes en general. Esto le llevó a componer obras en torno a Goya, Lorca o Juan Ramón Jiménez que llevan por título 24 Caprichos de Goya, Romancero Gitano o Platero y yo.

El compositor empezó a tocar el piano de niño gracias a su madre y abuelo materno. En un principio desarrollaba esta actividad a espaldas de su padre, el cual veía la música y la ejecución del piano una actividad dedicada a las "señoritas". Al padre de CastelnuovoTedesco siempre le pareció más adecuado que se dedicase a la medicina, lo que hizo que el compositor tuviese que simultanear estudios. No obstante, la delicada salud del compositor durante toda su vida hizo que tuviera que abandonar en su juventud los estudios de medicina para dedicarse solo a la labor compositiva.

\footnotetext{
14 También podemos encontrarlas en Jiménez (2012).

${ }^{15} \mathrm{La}$ autora nos descubre que entre los papeles que se conservan del poeta en la "Sala Zenobia-Juan Ramón Jiménez" de la Universidad de Río Piedras en Puerto Rico, Carmen Jiménez Lapeña ha encontrado recientemente "dos bocetos" escritos por el poeta sobre la fábula de Polifemo y Galatea para "dar motivo a la música de Falla”. Trabajó sobre este libreto entre los años 1917 y 1923.

16 Además de Falla, Juan Ramón dejó anotados los nombres de otros músicos elegidos para que pusieran música a poemas suyos. En la "Sala Zenobia-Juan Ramón Jiménez" de la Universidad de Puerto Rico (signatura Proyectos, 2, 387) (Sanz, 1999).
} 


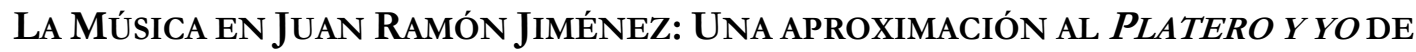 MaRio CASTELNUOVO-TEDESCO}

Se casó con Clara Forti en marzo de 1924 y tuvieron dos hijos, Lorenzo y Pietro. Su vida discurrió la mayor parte en el exilio, debido a los problemas que le supuso su procedencia sefardita. Castelnuovo-Tedesco vivió gran parte de su vida en EEUU y compuso bandas sonoras de películas para Hollywood. Por tanto, su exquisita técnica y formación europea le hizo abrirse paso en el mundo del cine. Los compositores que trabajaban allí pronto empezaron a envidiarlo debido a su facilidad y seguridad técnica; él escribía con pluma, mientras los demás usaban lápiz con el que borroneaban en cada momento. En un principio, Tedesco deseó orquestar su música, pero la dirección siempre se lo negaba, ya que en Hollywood había dos puestos diferenciados: uno era el de compositor y otro el de orquestador. Sin embargo, más adelante logró realizar ambos (Otero, 1987: 34).

Habría que destacar la relación de amistad que mantuvo con dos grandes músicos españoles, Manuel de Falla y Andrés Segovia. Si nos centramos en un primer momento en Falla, tendremos que señalar que Tedesco conoció al español porque realizó una crítica de su obra; el compositor español tuvo la oportunidad de leerla y posteriormente sus vidas se cruzaron. Falla le dedicó en una ocasión al compositor italiano estas palabras: "Somos los dos compositores más afortunados del mundo, tú por tener como ciudad a Florencia y yo a Granada" (Otero, 1987: 14).

Si nos centramos en la amistad con el guitarrista Andrés Segovia, tendremos que ahondar en determinados aspectos. El guitarrista y el compositor se conocieron en el año 1932 en el Festival Internacional de Venecia, que era el punto de reunión de las grandes figuras de la música.

Segovia instó a Tedesco a componer para guitarra, enviándole como ejemplos de composición para guitarra las Variaciones sobre un tema de Mozart de Fernando Sor y las Variaciones sobre las Folía de España de Manuel Ponce. A raíz de este hecho, Tedesco estudió a conciencia dichas obras y decidió hacer una pieza del mismo género, de manera que compuso las Variaciones a través de los siglos (Otero, 1987: 21).

A partir de ese momento, el compositor entabló una gran amistad con Segovia. El guitarrista español viajó en varias ocasiones a Florencia para acompañar a Tedesco y su familia en los momentos más duros, como fueron las navidades del exilio a América debido a la persecución nazi. Como muestra de agradecimiento, Tedesco escribió su primer concierto para guitarra. La Romanza se ha hecho muy conocida y refleja la nostalgia que el compositor siente al abandonar su tierra y los extensos campos de la Toscana.

Su labor compositiva para guitarra fue, por tanto, muy prolífica gracias al empeño que demostró Segovia. De esta labor nace la extensa obra para narrador y guitarra en torno a Juan Ramón Jiménez: Platero y yo.

Se trata de una obra en la que está presente la interdisciplinariedad, que dada a través de la relación existente entre la obra de Tedesco y la literatura, en la que van estrechamente ligadas texto y música. Siguiendo una reflexión de Debussy acerca de la relación entre ambas disciplinas (Helguera, 1993), en una entrevista publicada en marzo de 1911 en la 


\section{SILVIA NOGALES BARRIOS}

revista Musique: "Los músicos que no comprenden los versos, no deberían ponerle música. Solo pueden estropearlos".

Debussy citaba, por ejemplo, a Schumann y su incomprensión hacia la fina ironía de Heine. También señalaba que, al igual que han existido músicos que no comprendían los versos, ha habido poetas que no han comprendido la música ${ }^{17}$.

Este desencuentro entre música y literatura no lo ha manifestado Mario CastelnuovoTedesco, que nos deja como legado del repertorio guitarrístico una obra de unas dos horas de duración, basada en el libro de Juan Ramón Jiménez y compuesta entre 1958 y 1960. Así, la obra de Tedesco es la más ambiciosa para guitarra debido a su extensión. Durante la época en la que se gesta, el compositor italiano está sumergido en un "boom" creativo de repertorio para guitarra. Dicha obra, concebida para narrador y guitarra, consta de cuatro volúmenes con siete movimientos cada uno (cada libro puede durar unos 25 minutos). Según el musicólogo Ángelo Gilardino (2018), Tedesco compuso cuatro itinerarios paralelos a través del libro de Juan Ramón Jiménez, es decir, los movimientos de los cuatro volúmenes no son correlativos y no forman una unidad en su conjunto, sino que, como hemos dicho antes, son cuatro itinerarios distintos a través del libro pero con una coherencia argumental de principio a fin. Esta disposición está pensada por el propio compositor, ya que Segovia le había prometido grabar la obra en etapas distintas con el actor José Ferrer. Por lo tanto, Tedesco preparó cuatro selecciones (cuatro volúmenes), de siete movimientos cada una. Cada uno de los volúmenes podrían haberse grabado independientemente, y en cada uno se habría podido encontrar un recorrido de comienzo a fin a través de la historia de Platero y yo. También dice Gilardino (2018) que es posible escoger movimientos de distintos volúmenes para ser interpretados, y aun así la obra seguiría teniendo sentido, ya que también es concebida como un todo y tiene, por lo tanto, una unidad.

El proyecto entre Andrés Segovia y Ferrer no se llegó a materializar, por lo que el guitarrista grabó una selección de piezas sin narrador. Dicha decisión fue un tanto desacertada, porque la obra, al estar pensada para narrador y guitarra, depende del texto para su forma, expresividad y creación de imágenes. Existen partes musicales que, sin el texto, pierden parte de su sentido, ya que el trabajo de adecuación texto-música en esta obra es total. Así, Tedesco realiza una gran labor en dicha adecuación, propiciada en gran parte por la práctica cosechada en Hollywood en la adecuación de música e imagen, durante su etapa de compositor para cine.

17 Es lo que le pasó precisamente a Jules Renard con Ravel. Jules Renard mantiene un diálogo el 19 de noviembre de 1906 con Thadée Natanson y en ella expresa su total indiferencia hacia la música que pone Ravel a sus versos en prosa. Más adelante, el 12 de diciembre de 1907, se encara con el propio Ravel preguntándole después de dedicarle algunos adjetivos como "moreno, fino y rico", qué ha añadido a sus Histoires Naturelles. Ravel le contesta que su intención no era añadir nada, sino intentar decir con música lo que Renard decía con palabras. Ravel le dijo: "Yo siento y pienso en música y me gustaría pensar y sentir lo mismo que usted". Pero el esfuerzo de Ravel fue en vano ya que la mente cerrada de Renard no le permitió disfrutar de uno de los mayores homenajes que jamás le hayan podido hacer y además de un maestro como Ravel. 


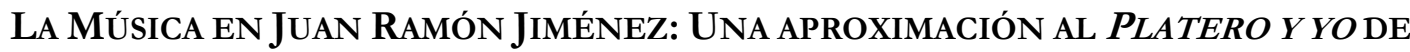 Mario CASTELNUOVO-TEDESCo}

\subsection{ANÁLISIS DEL PRIMER MOVIMIENTO}

El primer movimiento de esta obra se corresponde con el primer capítulo del libro de Juan Ramón Jiménez. Tanto el libro como la obra de Tedesco y esta primera pieza llevan el nombre de Platero y yo. Este movimiento ha sido brevemente analizado por la profesora Alicia Díaz de la Fuente (2008), para que apareciese en el libreto del disco que sobre esta obra realiza el guitarrista Miguel Ángel Romero en $2008^{18}$.

En este primer movimiento se describe al personaje en torno al cual gira la historia de Juan Ramón, que no es otro que el burrito Platero.

\begin{tabular}{|c|c|c|}
\hline \multicolumn{3}{|r|}{ ESTRUCTURA GENERAL } \\
\hline PARTES & COMPASES & PROCESOS \\
\hline $\mathbf{A}$ & 1 al 17 & $\begin{array}{l}\text { Introducción instrumental cc. } 1 \text { al } 8 \\
\text { 1. Platero es pequeño, peludo, suave; tan blando por fuera, que se diría } \\
\text { todo de algodón, que no lleva huesos. } \\
\text { 2. Solo los espejos de azabache de sus ojos son duros cual dos escarabajos } \\
\text { de cristal negro. }\end{array}$ \\
\hline B & 18 al 25 & $\begin{array}{l}\text { 3. Lo dejo suelto, y se va al prado, y acaricia tibiamente con su hocico, } \\
\text { rozándolas apenas, las florecillas rosas, celestes y gualdas... }\end{array}$ \\
\hline C & 26 al 37 & $\begin{array}{l}\text { 4. Lo llamo dulcemente: "¿Platero?" } \\
\text { 5. y viene a mí con un trotecillo alegre que parece que se ríe, en no sé qué } \\
\text { cascabeleo ideal... } \\
\text { 6. come cuanto le doy }\end{array}$ \\
\hline $\mathbf{D}$ & 38 al 46 & $\begin{array}{l}\text { 7. Le gustan las naranjas mandarinas, las uvas moscateles, todas de ámbar, } \\
\text { los higos morados, con su cristalina gotita de miel... }\end{array}$ \\
\hline $\mathbf{E}$ & 47 al 51 & $\begin{array}{l}\text { 8. Es tierno y mimoso igual que un niño, que una niña...; pero fuerte y } \\
\text { seco por dentro, como de piedra. }\end{array}$ \\
\hline $\mathbf{F}$ & 52 al 70 & $\begin{array}{l}\text { 9. Cuando paso sobre él, los domingos, por las últimas callejas del pueblo, } \\
\text { los hombres del campo, vestidos de limpio y despaciosos, se quedan } \\
\text { mirándolo: } \\
\text { 10. -Tien'asero...-Tiene acero. } \\
\text { 11. Acero y plata de luna, al mismo tiempo. }\end{array}$ \\
\hline
\end{tabular}

Tabla 1.

- Parte A, compases 1 al 17.

18 Existen numerosas grabaciones de este movimiento, en trabajos como el anteriormente mencionado del
Guitarrista Ángel Romero y Clément Riot (el cual se puede encontrar en el siguiente enlace:
https://itunes.apple.com/mx/album/platero-y-yo/304736076), la versión de Frank Koonce y Marisol
Membrillo, lanzada en 2014 y que recoge 13 movimientos (https://itunes.apple.com/es/album/platero-y-
yo/950133986) y la propuesta de concierto interdisciplinar de la actriz Esther Acevedo y Silvia Nogales. Esta
propuesta trata de dar una "vuelta de tuerca" a la obra de Tedesco, llevándola al público de una forma
dramatizada e interdisciplinar, que favorezca su recepción, apoyándose en elementos visuales y escénicos
como las ilustraciones de la diseñadora Gallega Laura Ferreiro. Se puede obtener más información en
http://www.silvianogales.com/las-seis-doncellas-de-juan-ramon-jimenez/ y ver la interpretación en
https://www.youtube.com/watch?v=e5tqLU bxSY\&t=179s 


\section{SILVIA NOGALES BARRIOS}

El movimiento se inicia con un compás de 12/8 con una pedal en las notas agudas que se corresponden con las notas "mi" y "si". En el bajo aparece una melodía por cuartas que va a alertarnos de que la modalidad de esta pieza se puede circunscribir en un mi dórico por la presencia del fa y do sostenido. A este motivo lo podríamos llamar "a".

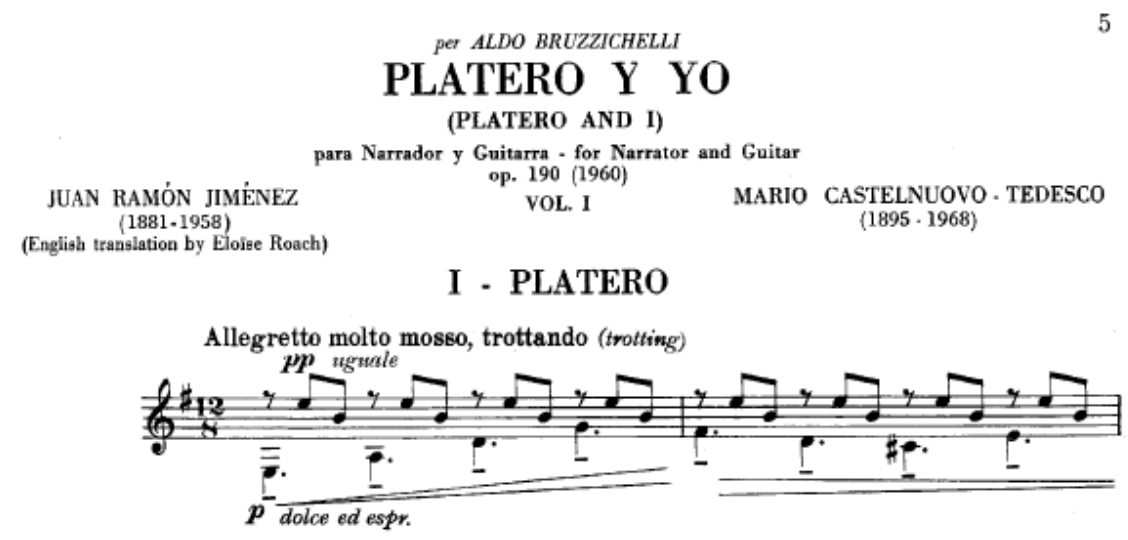

Fig. 1.

El hecho de que el compositor elija la modalidad para esta obra en lugar de escribir una pieza puramente tonal, podríamos justificarlo desde distintas perspectivas. La primera, por idiomatismo y tipología del instrumento para el que está escrita. La guitarra, por su afinación y características, es un instrumento que se comporta muy bien dentro de la modalidad; bien es sabido que los impresionistas como Debussy inspiraban sus obras en una guitarra fantasmagórica, siendo su música una alegoría de este instrumento. Lo mismo pasa con otros compositores de la época como Albéniz, quien, aunque no compuso para el instrumento, sí es cierto que su música bebe constantemente de los recursos técnicos, melódicos y estéticos de la guitarra. Hemos podido ver cómo las transcripciones de piezas como Asturias, Granada, Córdoba, etc., funcionan perfectamente en el instrumento. Acercándonos al libro de Jorge de Persia En torno a lo español en la música del siglo XX se puede leer:

Los compositores utilizaban los recursos formales de la guitarra de los guitarristas populares trasladándolos a piano o a la orquesta. Evocación, un ejemplo entre muchos, pieza que abre la serie pianística de Iberia de Isaac Albéniz, muestra una melodía con acompañamiento guitarrístico. Pero este autor, que junto a Granados era "la representación de lo español en París", nunca compuso para la guitarra, solo evocó sus características en el piano. La guitarra únicamente servía de modelo, de referencia, para intentar una estilización o un rasgo característico del "lenguaje español".

Imitación, evocación, impresión, descripción, atributos aplicados a formas musicales difícilmente definibles, son recursos usados para caracterizar muchas piezas y están muy 


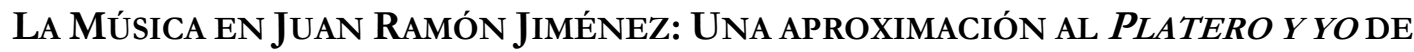 MaRio CASTELNUOVO-TEDESCO}

presentes en la música de la época. Y la guitarra aparece aquí representada en esas distintas dimensiones, de la misma manera que lo hace en las artes plásticas o en la producción literaria.

Wade alaba precisamente las dimensiones guitarrísticas de la obra para piano de Albéniz, puesta en evidencia en las transcripciones de su contemporáneo Francisco Tárrega o las más tardías de Andrés Segovia. De Persia (2003: 205-206)

Otra razón para elegir la modalidad se podría encontrar en el texto. Platero y yo es un texto básicamente impresionista y para ello el compositor utiliza una música de este estilo, la cual está encarnada en el instrumento que resurge de las cenizas precisamente en el impresionismo, tal y como expresa Falla al componer el Homenaje a Debussy para guitarra:

Falla reconoce en esta pequeña obra su deuda con Debussy y, por medio de la guitarra, evocada por el maestro francés en su música, intenta expresarse como él lo hiciera, sin giros específicamente "españoles" sino más bien atribuidos, como el de la habanera, cerrando el círculo de esta comunicación que remite al ámbito de lo trascendente, de la evocación. El ritmo de habanera característico recuerda, como el propio autor señala, su presencia en Les parfums de Ia nuit y en La Puerta del Vino, estrechamente ligados por ese común elemento a la Soirée dans Grenade, pieza que despertó un gran interés en el músico gaditano, quien decidió terminar el Homenaje a su amigo y maestro con una cita de ella. De Persia (2003: 200)

Podemos extraer unas interesantes palabras de Falla con respecto al tema en el capítulo de Jorge de Persia titulado La guitarra entre el mito y la metáfora. Así, Manuel de Falla expresa que "Claudio Debussy ha escrito música española sin conocer España; mejor dicho, sin conocer el territorio español, lo cual es bien distinto” (De Persia, 2003: 207).

Según de Persia, para Falla, Debussy evocaba España en su música por medio de elementos rítmicos y armónicos, y en el centro de la cuestión estaba la guitarra, ya que utilizaba giros característicos que preludian o acompañan a la copla. La obra Iberia de Debussy no es música española, son un conjunto de impresiones que nuestro país producía en el compositor francés. El tema generador de la obra según Falla es una especie de sevillanas, que evoca danzas "de una banda de guitarras y de bandurrias". Sin embargo, lo más importante son los fenómenos armónicos que aparecen en la obra de Debussy y que Falla señala como realizados "con la guitara de la manera más espontánea del mundo" (De Persia, 2003: 207).

Si continuamos con el análisis y nos fijamos en el inicio, podemos ver que la pieza tiene 8 compases de introducción (cc. 1-8) en los que aún no se ha personado el texto. La guitarra tiene todo el protagonismo en esta parte, en la cual ya podremos atisbar varios rasgos de las relaciones entre texto y música. Vemos cómo se mantiene la nota pedal en las notas "mi" y "si" que antes mencionamos, siendo el bajo el que realiza la parte melódica. El motivo rítmico del silencio de corchea junto a las dos corcheas que llamamos "a" va a 


\section{SILVIA NOGALES BARRIOS}

representar a Platero, en concreto, al trotecillo del burro. Vemos en esta ocasión cómo Tedesco encarna con la música la figura del burrillo, introduciendo al público en la historia de una forma gradual que les haga familiarizarse con el ritmo, para que se produzca una asociación entre el trote y el motivo rítmico y melódico que se da. Podemos también destacar el hecho de que al inicio del primer movimiento tenemos la indicación para el intérprete de Allegretto moltto mosso, trottando.

\section{I - PLATERO}
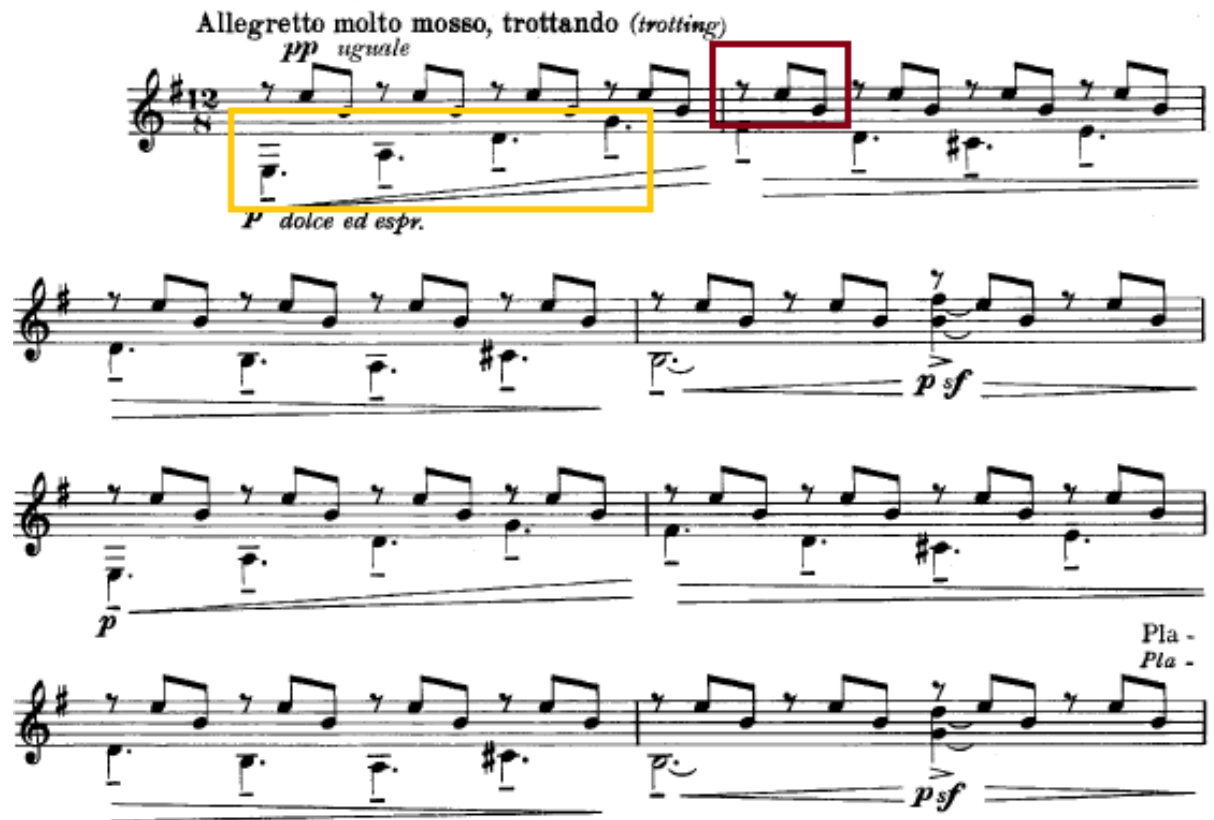

Fig. 2.

En el compás 8 aparece por primera vez el texto y con él se producen algunos cambios desde el punto de vista musical, como son la adición de una segunda nota en el bajo a distancia de sexta, junto a una nueva alteración como es el mi sostenido. Estos cambios nos hacen presente el inicio de la historia.

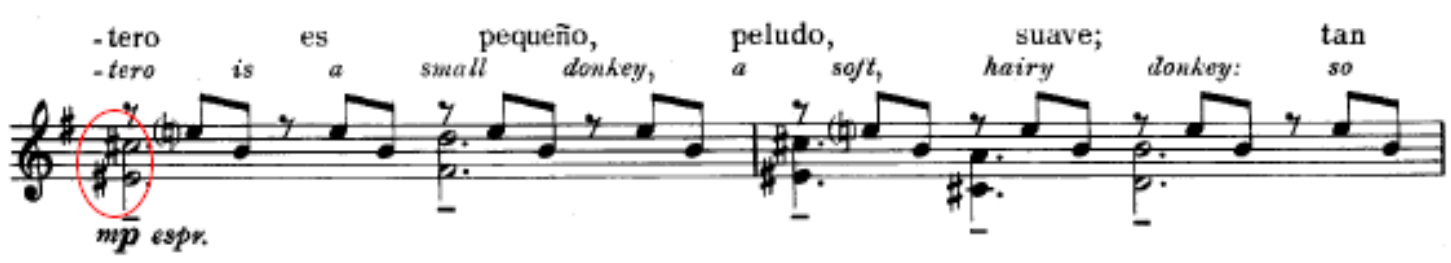

Fig. 3.

En los compases 15 y 17 asistimos a un cambio textural en la partitura. La pieza viene escrita hasta el momento bajo un colchón dado por la nota pedal que encarnan el 


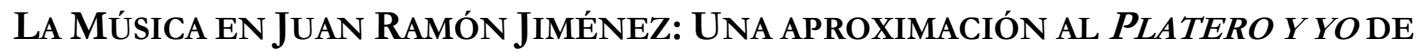 MaRio CASTELNUOVO-TEDESCO}

"mi" y el "si" del registro agudo en corcheas, que posteriormente se transforman en los compases 15 y 17 en acordes de densidad 4. Estos nuevos acordes aparecen con una figuración de corchea, la cual se encuentra rodeada de silencios para dar una sensación de sonido seco, casi stacatto. Hay un cambio relevante en la música, la cual viene de un legato con dulzura bajo la indicación de piano, para posteriormente en los compases indicados irrumpir bajo un sforzando con los acordes secos, rompiendo así con la dulzura y paz anterior.
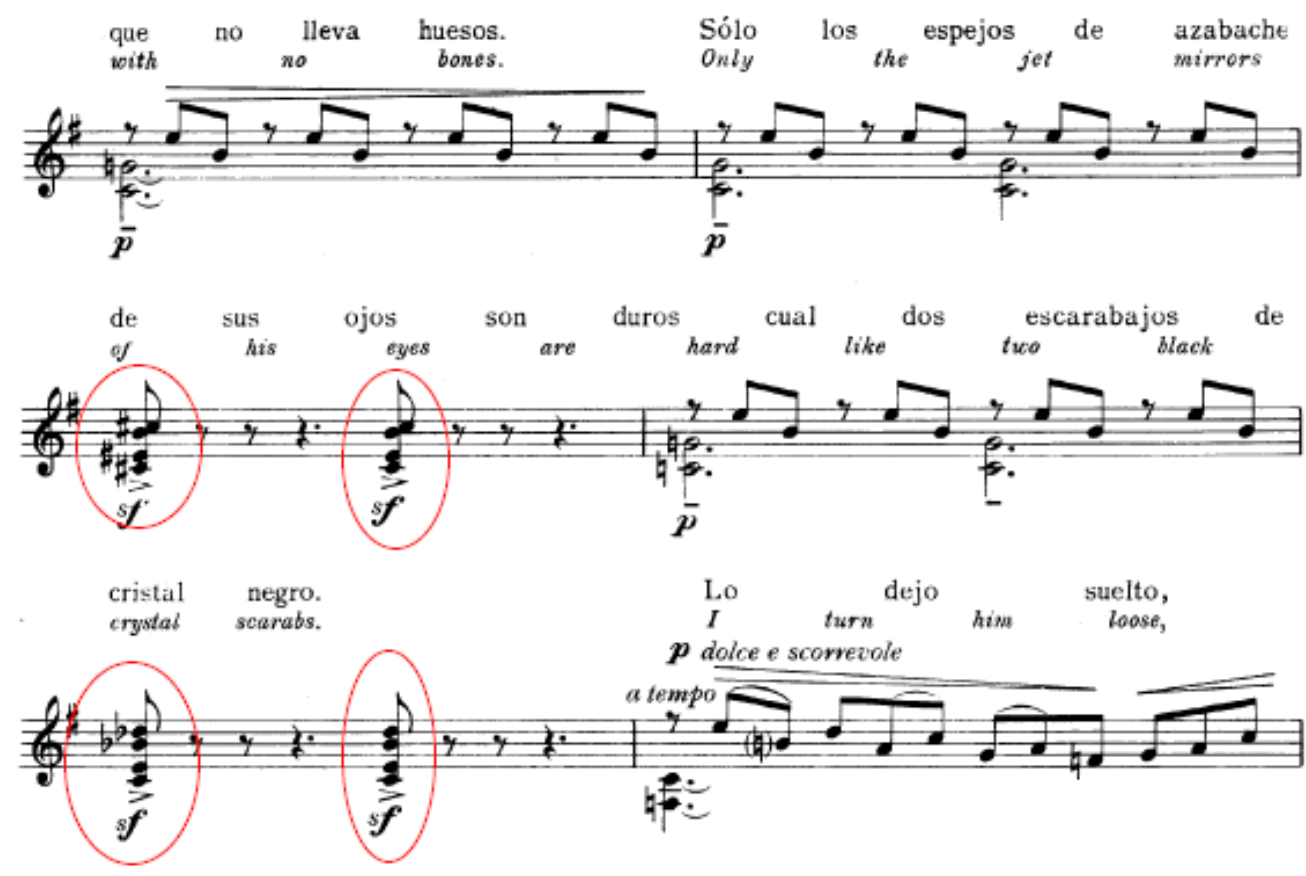

Fig. 4.

Estos recursos introducidos por Tedesco no son aleatorios. Se quiere reforzar y resaltar las palabras “ojos duros y cristal negro”, por lo que el compositor realiza esos cambios de textura, dinámica, etc.

- Parte B, compases 18 al 25.

En el compás 18 aparece una nueva frase textual, «Lo dejo suelto, y se va al prado, y acaricia tibiamente con su hocico, rozándolas apenas, las florecillas rosas, celestes y gualdas...", que se alarga hasta el compás 25 . En este punto se produce otro cambio de textura en la música, incluso de modo, apareciendo el Fa lidio del compás 18. Esto nos hace pensar, por tanto, que se vuelve a reflejar en la música los cambios que se producen en el texto; vemos cómo la forma musical viene dada a través del mismo, pues los contrastes que tienen lugar entre las distintas secciones musicales vienen influenciados por él. En esta ocasión (c. 18), aparece el tresillo, que es una variación del motivo que al principio de la pieza se asemejaba con el trote (motivo "a"). 


\section{SILVIA NOGALES BARRIOS}

Si nos fijamos en las relaciones que se van estableciendo entre texto y música, observamos que cada tipología textual hará aparecer unos tipos de verbos, sintagmas nominales, etc., concretos. Al inicio de la pieza se está describiendo al que será el personaje principal, Platero. Podríamos decir, que en esta primera parte estaríamos ante un texto de tipología descriptiva, y como tal, prima lo estático. La música refleja ese estatismo mediante la nota pedal, que a su vez es el motivo rítmico y melódico que se relaciona con Platero. Por lo tanto, vemos cómo las palabras están relacionadas con la figuración que se elige, propiciando en un principio lo estático pero posteriormente cambiando a momentos más fluidos. Un ejemplo claro lo tendríamos cuando el motivo que se identifica con el trote de Platero se convierte en unos tresillos en legato, los cuales dan una sensación de fluidez coincidiendo con el cambio textual. Cuando aparecen se modifica la percepción para el oyente, estableciendo contrastes que concuerdan con la historia. Por tanto, el texto está relacionado con la figuración que el compositor elige en cada momento.

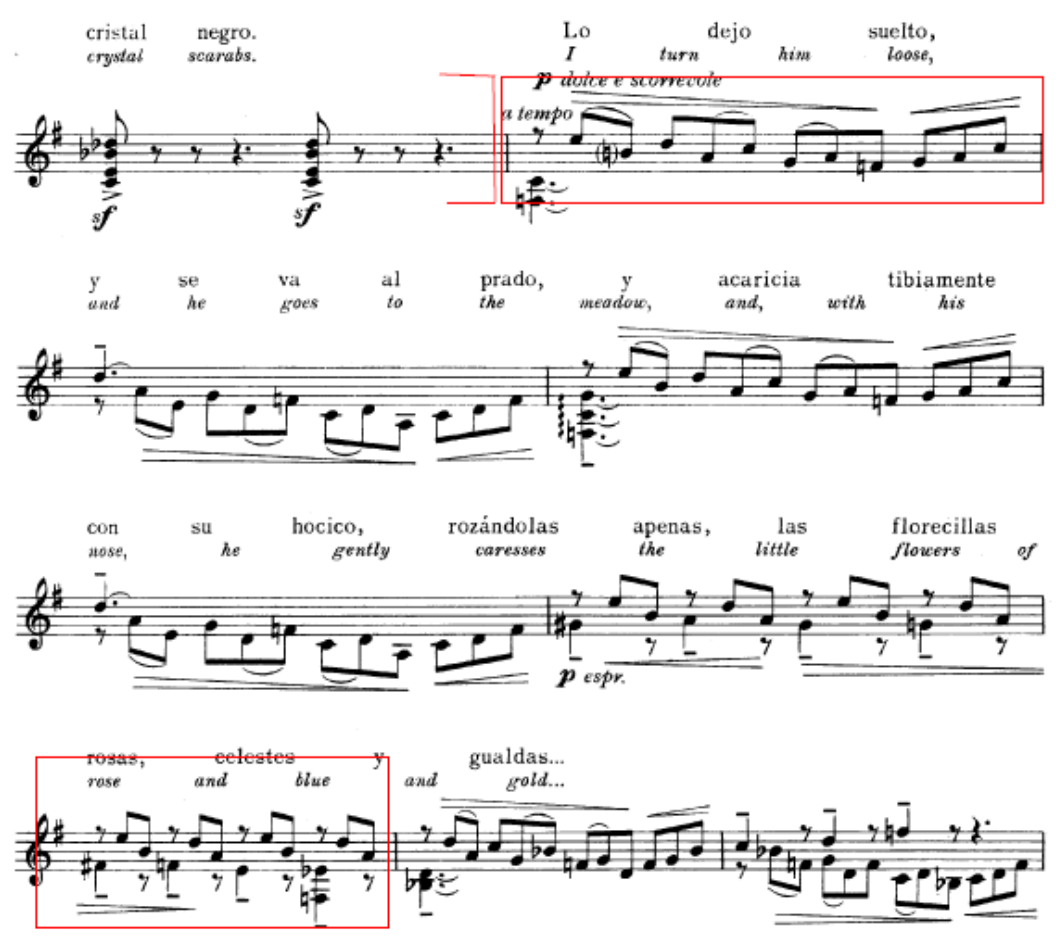

Fig. 5.

Al motivo de los tresillos que aparece en el compás 18 y sucesivos podríamos llamarlo "a" prima ("a"). Si atendemos a la historia, en este punto ya no se está describiendo a Platero físicamente, sino que se está hablando de lo que el animal hace cuando se encuentra suelto en el prado; el escritor, incluso, describe el paisaje. En el compás 23 vuelve a aparecer el motivo que se identifica con Platero ("a") y cambia hacia lo que podría parecer un sol menor para concluir dicha frase. 


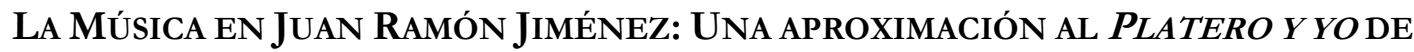 Mario CASTELNUOVO-TEDESCo}

\section{- Parte C, compases del 26 al 37.}

Si avanzamos hasta el compás 26, se observa que sucede exactamente lo mismo. Se inicia una nueva frase en el compás 27, “Lo llamo dulcemente: ¿Platero?”, dándose una nueva textura junto a distintos cambios armónicos. La frase anterior es una pregunta retórica, una apelación a Platero. Al final de la misma, en el compás 29, observamos la presencia de la doble barra en la partitura, que hace que destaque la pregunta retórica. En esta ocasión, en el texto se refleja cómo el dueño del burro, que no es otro que Juan Ramón Jiménez, lo llama dulcemente. En ese momento la música imita al texto reflejando también una llamada que se corresponde con las notas "sol", "sib", "re" y "fa" becuadro. En el compás siguiente (c. 27), se da un cambio de compás $(4 / 4)$, produciéndose una inflexión, una pequeña modulación cromática. Además, en este lugar encontramos una especie de dominante con séptima, produciéndose la inflexión al elevar un semitono el sol, manteniendo el re igual y bajando otro semitono el fa del compás anterior. Es decir, se produce una inflexión cromática; no se utiliza un acorde pivote. Ese acorde al que se ha llegado mediante cromatismos produce la necesidad de resolver.

Del compás 30 al 35 encontramos un 12/8 y se inicia otra frase: “y viene a mí con un trotecillo alegre que parece que se ríe, en no sé qué cascabeleo ideal...”. En el compás 30 se produce una resolución, a través de un acorde por cuartas sobre un movimiento de tónica-dominante. Esta parte funciona casi con la misma lógica que al principio. Volviendo a los compases 27 y 28, observamos cómo melódicamente estos son una imitación de lo que va a realizar el texto, es decir, una imitación de la pregunta “¿Platero?”, en la cual el compositor también ha señalado distintas alturas para el narrador como podremos observar a continuación.

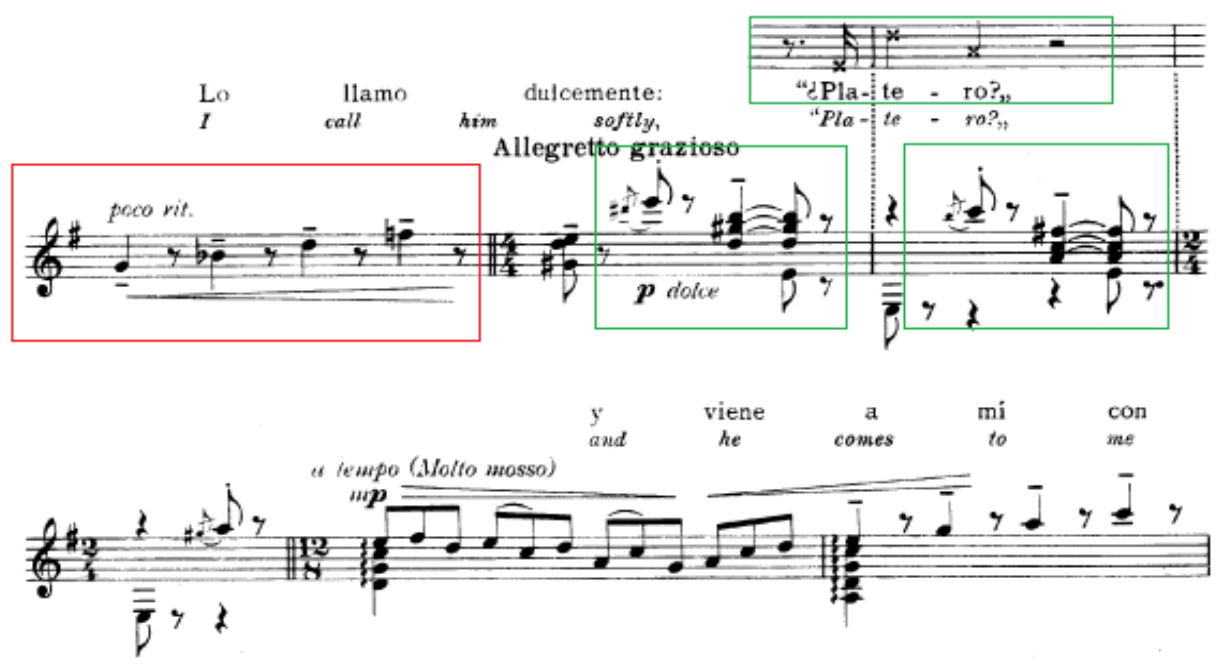

Fig. 6.

Además, tenemos que hablar del cambio de tempo que se produce del Allegretto grazioso al a tempo (Molto mosso). Como vemos, el compositor también establece dichos contrastes mediante los cambios de dinámica y timbre. Un ejemplo de ello lo tendremos si volvemos a los cc. 26-29, donde las dinámicas acompañan al texto ayudándole a comunicar 


\section{SILVIA NogALES BARRIOS}

lo que se pretende. Así queda reflejado en el crescendo del compás 26, el piano dolce del 27, etc. Esta cuestión no es un hecho aislado, sino que se va a dar durante todo el movimiento.

En el compás 29 el verso se queda brevemente en suspenso; podemos decir que a partir de este momento se está esperando una respuesta por parte de Platero. La respuesta a la llamada la encontramos a partir del compás 30 y hasta el 35, donde el texto dice " $\boldsymbol{y}$ viene a mí con un trotecillo alegre que parece que se ríe, en no sé qué cascabeleo ideal...". En este momento vemos cómo vuelve a aparecer el motivo que se ha asemejado al trotecillo del burro y, en concreto a Platero, un motivo que aparece cuando habla de cómo el burrillo vuelve hacia el dueño con un trotecillo alegre atendiendo a la llamada.
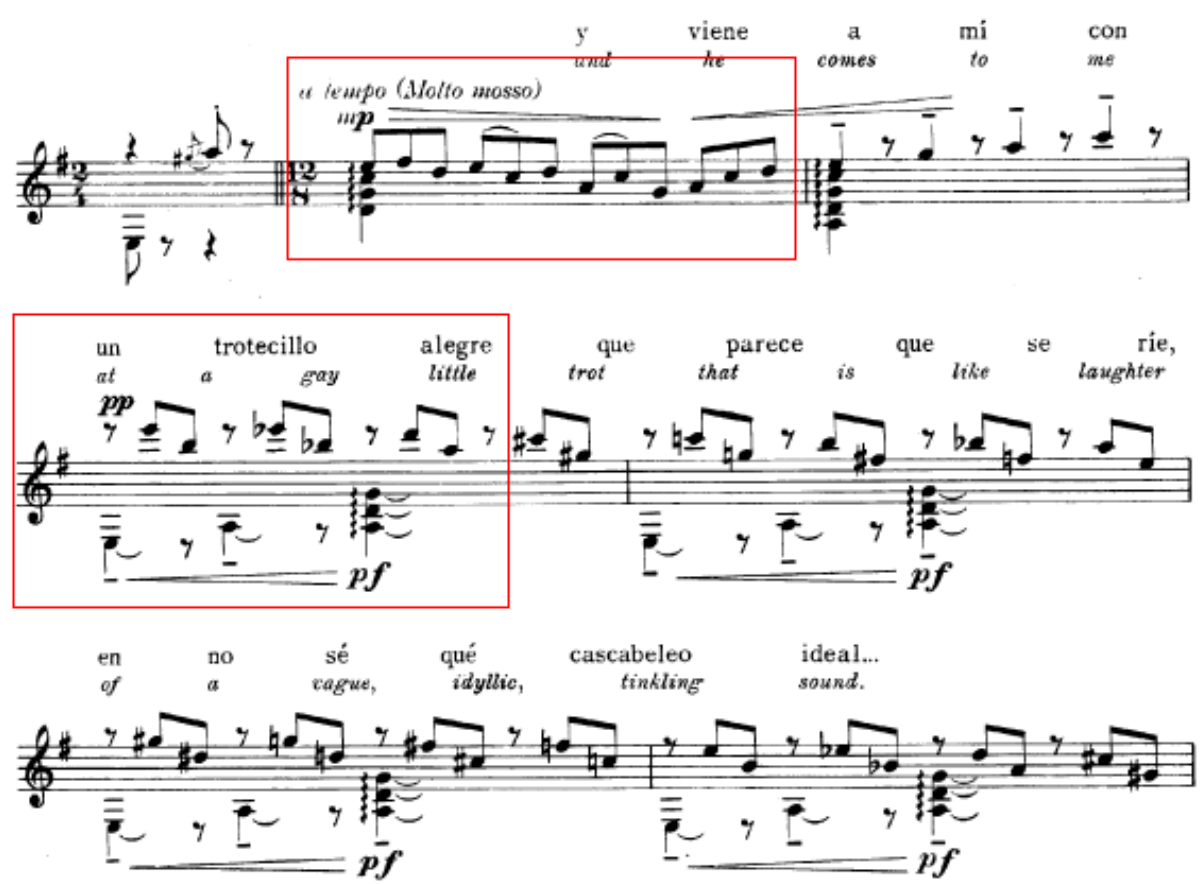

Fig. 7.

En el compás 36, existe una continuación musical que viene de los compases anteriores; el texto se prepara para la realización de una enumeración que queda reflejada en la siguiente frase: "Come cuanto le doy".

\section{- Parte D, compases 38 al 46.}

Realmente es en el compás 38 cuando se produce el contraste, tanto musical como textual. Como podemos observar, se hace una enumeración en la que se va dando una gradación hasta higos morados. Si miramos la armonía, vemos cómo los acordes que aquí se presentan desde el compás 36 hasta el 45 se dan mediante movimientos cromáticos con una nota pedal en el bajo. Al principio esa nota pedal es re; en el compás 40 se transforma en un fa. Como vemos en el compás 38, primero se mueve un semitono ascendente la nota aguda del acorde (va de un "la" a un "sib"), la nota central del acorde desciende, sin embargo, un semitono hacia el fa becuadro, y el bajo se mantiene. En el siguiente compás 


\section{La Música en Juan Ramón Jiménez: Una APRoximación al Platero y yo de MaRio CASTELNUOVO-TEDESCO}

tanto la nota aguda del acorde como la central descienden un semitono, pero el bajo continúa siendo re. Estos movimientos cromáticos que existen en los cc. 38-41 llevan a la palabra "ámbar", donde hay un acorde de Mi de densidad cuatro. Es curioso el hecho de que todos los compases anteriores en los que la textura cambió a acordal, con acordes placados, estén formados por triadas cambiantes mediante movimientos de semitono que nos dirigen hacia la palabra "ámbar", como hemos dicho antes apareciendo un acorde de densidad 4. Esto no es más que un nuevo recurso utilizado por el compositor para resaltar las palabras clave del texto. En los compases siguientes (cc. 42-45) vemos cómo se da lo mismo que antes, pero con el bajo fa, moviéndose todo el pasaje hacia "gotita de miel", donde aparece el acorde aumentado.

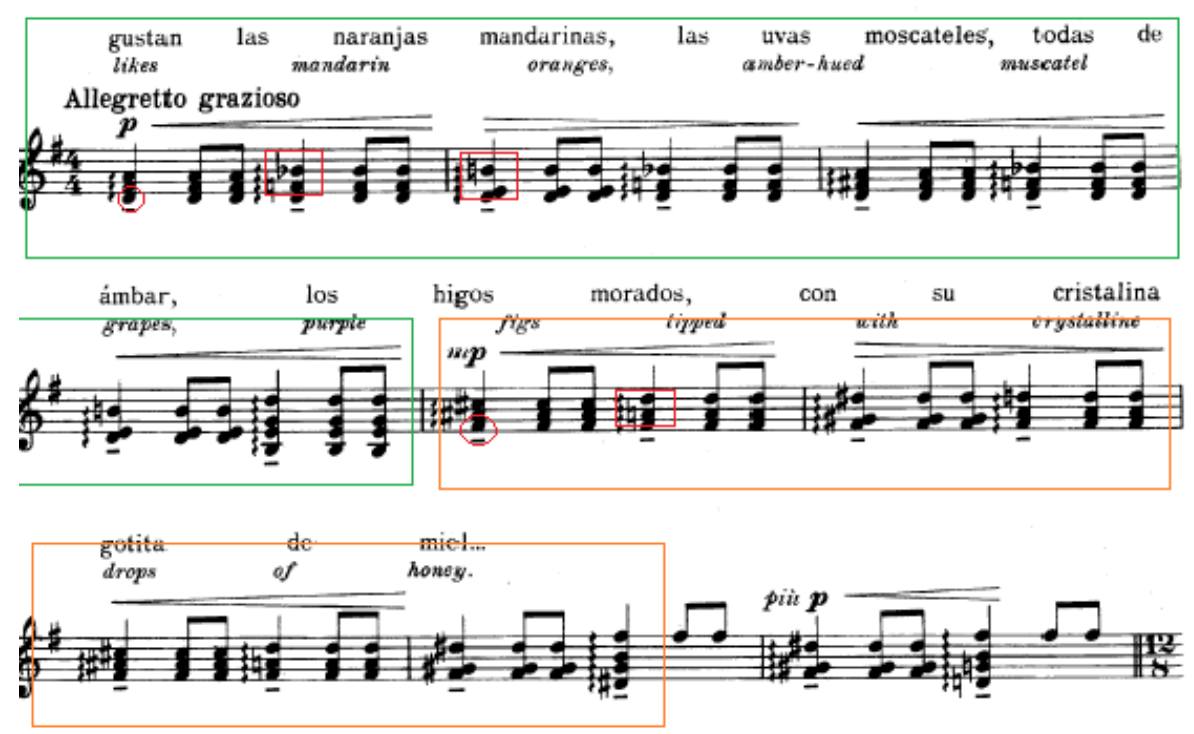

Fig. 8 .

\section{- Parte E, compás 47 al 51.}

Si seguimos con el análisis, en el compás 47 hay un nuevo cambio de compás a un $12 / 8$ y también se modifican las dinámicas e indicaciones de tiempo, que van de un Allegretto grazioso de los compases anteriores a un Tempo I, (Mosso scorrevole). Lo que se da a partir del compás 47 nos recuerda sin duda a los tresillos que aparecen cuando en el texto se reflejan las palabras del compás 18, "lo dejo suelto y se va al prado y acaricia tibiamente con su hocico..." (motivo a'). En este momento se produce un nuevo cambio en el carácter del texto; hemos pasado de una especie de enumeración a describir nuevamente a platero. Este cambio dirige a la música hacia el legato, contrastando con los acordes placados y más secos que observamos anteriormente. También se vuelve a identificar ese tresillo que encarna a Platero, que nace del motivo de dos corcheas que identificábamos con el trote. En el compás 50 hay de nuevo un tetradordo en el cual se elude el cuarto. En este momento la música se prepara para recibir de nuevo los acordes secos en semicorcheas, que también aparecían cuando se decía que los ojos de Platero eran 


\section{SILVIA NOGALES BARRIOS}

duros como “dos escarabajos de cristal negro" (cc. 16-17). Lo que se pretende señalar en el compás 51 es que “platero es fuerte y seco por dentro como de piedra". En el momento que aparece la palabra piedra lo hace acompañada un acorde de densidad 5, con lo cual llama la atención la importancia que Tedesco quiere atribuir a esa palabra, haciéndola resaltar con su música. Si observamos lo que sucede durante la pieza, veremos que los cambios de textura se producen porque en el texto se juega con un doble nivel: se hace una descripción de Platero tanto interna como externa. También hay una reiteración durante toda la pieza de lo "blando", "suave", lo "duro", etc., haciendo contraposiciones que se dejan ver en la música mediante la articulación y la textura, que pasa del legato y ligereza a acordes secos de mayor densidad.
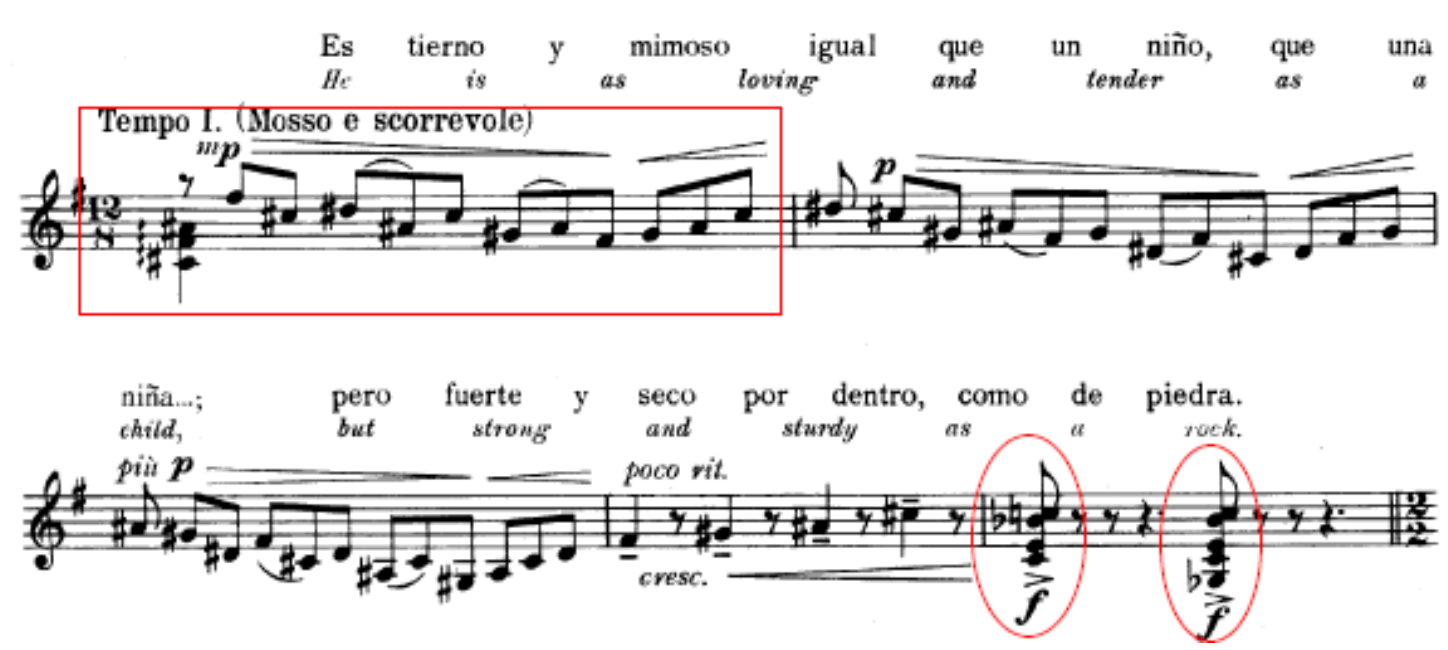

Fig. 9.

- Parte F, compases del 51 al 70.

A partir del compás 52 se produce un nuevo cambio musical tanto de textura como de motivos y armonía. Esto tiene lugar nuevamente para acompañar al texto, que en este caso ha pasado de ser descriptivo a ser narrativo, donde el escritor cuenta lo que pasa cuando pasea sobre Platero los domingos en las callejuelas. En estos compases (cc.52-59), vuelve a darse una variación del motivo de dos corcheas sincopadas que se identifica con el trote de Platero. El carácter cambia mediante las indicaciones de tiempo (un poco Moderato) y el nuevo compás de 2/2. Aparte, vemos que los movimientos que se van produciendo en las voces son parecidos a los que se daban cuando encontrábamos la enumeración del compás 38: aquí también hay una nota pedal en el bajo, que en esta ocasión lo forman dos notas separadas a distancia de $5^{a}$ ( $f a$ y do) y luego las dos corcheas fa y do. Los acordes que se forman encima de los bajos van conduciendo sus voces por semitonos, ascendentes y descendentes. Podemos observar que de nuevo la textura ha cambiado. 


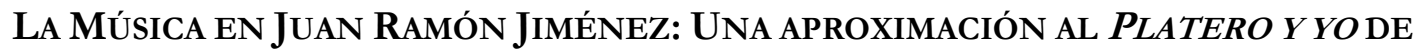 MaRio CASTELNUOVO-TEDESCO}

$$
\text { Cuando paso sobre él, los }{ }_{\text {When }}^{\text {domingos, }} \text { por } \text { Sundays }_{\text {through }}^{\text {las }} \text { the }_{\text {lanes }}^{\text {últimas }} \text { in the }
$$
Un poco Moderato (in 2)

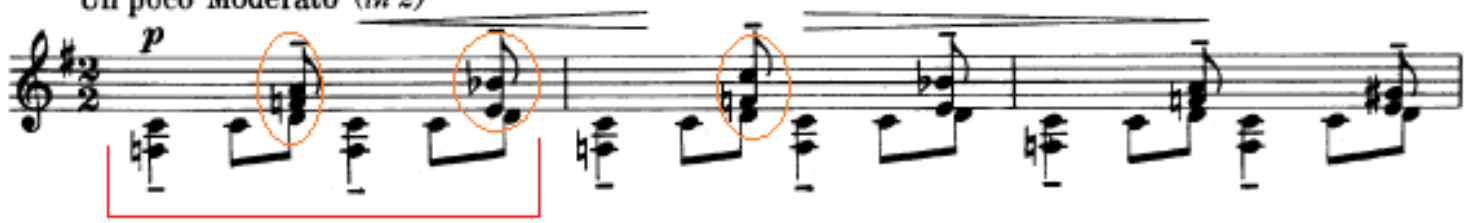

Fig. 10.

En el compás 60 vuelve a modificarse la textura, pero en este caso es por las palabras "asero" (pronunciación andaluza de acero) y "acero". En los cc. 60-63, vuelven a darse esos acordes de densidad cuatro que aparecían en "ojos duros como dos escarabajos de cristal negro" (cc. 15 y 17) o en “seco por dentro como de piedra” (c. 51). Llegados a este punto, podemos decir que se produce una isotopía del movimiento, es decir, hay una continuidad de campos semánticos a lo largo de la misma, concretamente de lo "blando" y lo "duro"; cuando estas palabras aparecen se destacan con los acordes secos. El compositor actúa acentuando palabras clave para la interpretación del texto, generalmente de adjetivos. Vemos aquí un rasgo impresionista del texto debido al valor que el escritor da a los adjetivos; esto va en concordancia con la música, que también es impresionista, lo cual se puede observar en su modalidad, aunque hay veces en la obra que algunos de los movimientos modales que se producen tienen una lógica de movimiento de fundamentales que entroncan con lo tonal.

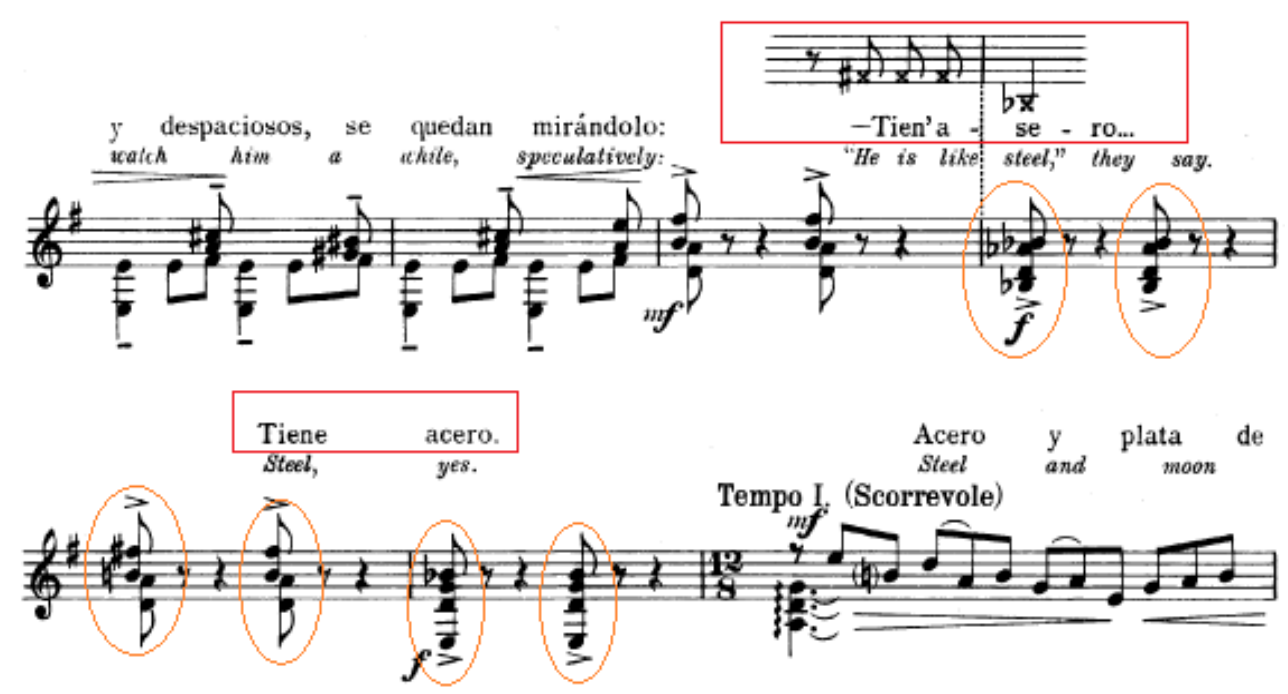

Fig. 11.

En el compás 64 se vuelve a modificar la textura y aparece el Tempo I (Scorrevole); aparte, hay un cambio de tempo a un 12/8. En los compases 64 y 65, donde en el texto se puede leer “Acero y plata de luna al mismo tiempo", aparecen los tresillos que dan la sensación de 


\section{SILVIA NOGALES BARRIOS}

legato y suavidad en contraste con lo anterior. Esos tresillos han aparecido anteriormente en compases como 18-21, 30, 47-49, etc., y ayudan a resaltar adjetivos relacionados con lo suave o blando. Por ejemplo:

\section{Cc.47-49: “es tierno y mimoso igual que un niño que una niña...”.}

Cc. 64-65: "acero y plata de luna al mismo tiempo"; se contrapone al acero, con características de fortaleza y dureza, con la plata de luna, que es frágil y bella, más delicada.
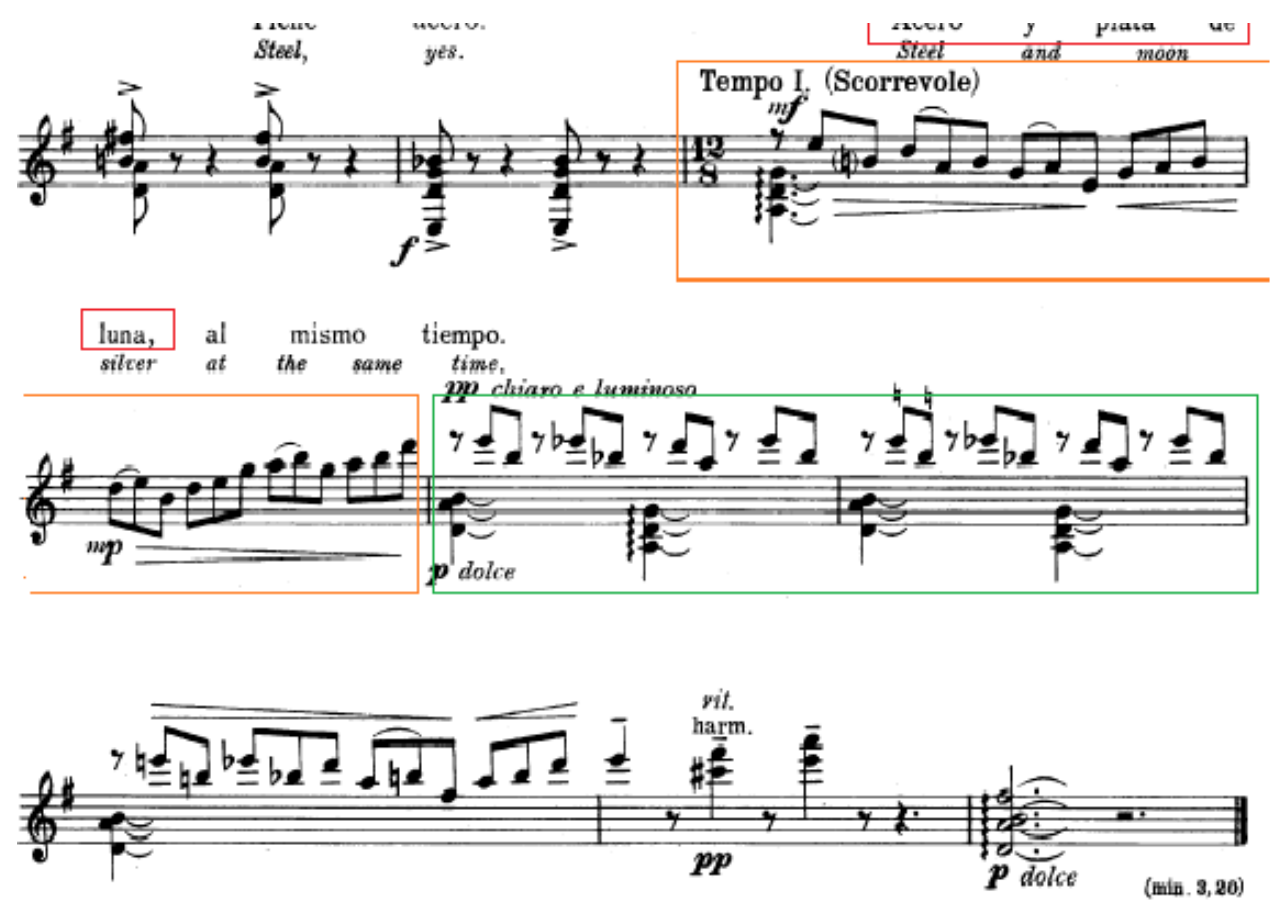

Fig. 12.

Al final de la obra vuelve a hacer acto de presencia el motivo del trotecillo, que finaliza en el registro más agudo que se ha podido escuchar en toda la pieza. Generalmente Juan Ramón Jiménez utiliza imágenes, metáforas ascendentes, es decir, que elevan la realidad a la que se refieren. El término real es ensalzado y ponderado positivamente; esto se ve reflejado en la música mediante gestos melódicos que tienden al agudo.

También es importante el ritmo de la corchea sincopada que aparece durante todo este movimiento, actuando la música como una abstracción de un rasgo concreto. Aunque el texto desarrolla varias cosas, casi el eje por el cual se establece la comunicación entre texto y música es el compás, la síncopa que imita al trote. Ese motivo es modificado cuando quiere obtener agilidad, y a veces queda interrumpido para destacar ciertas palabras como "cristal negro", "acero", "duros", etc., pero siempre encontramos un retorno al motivo del trote que encarna a Platero. 


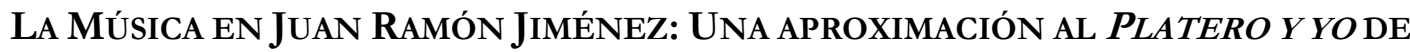 Mario CASTELNUOVO-TEDESCo}
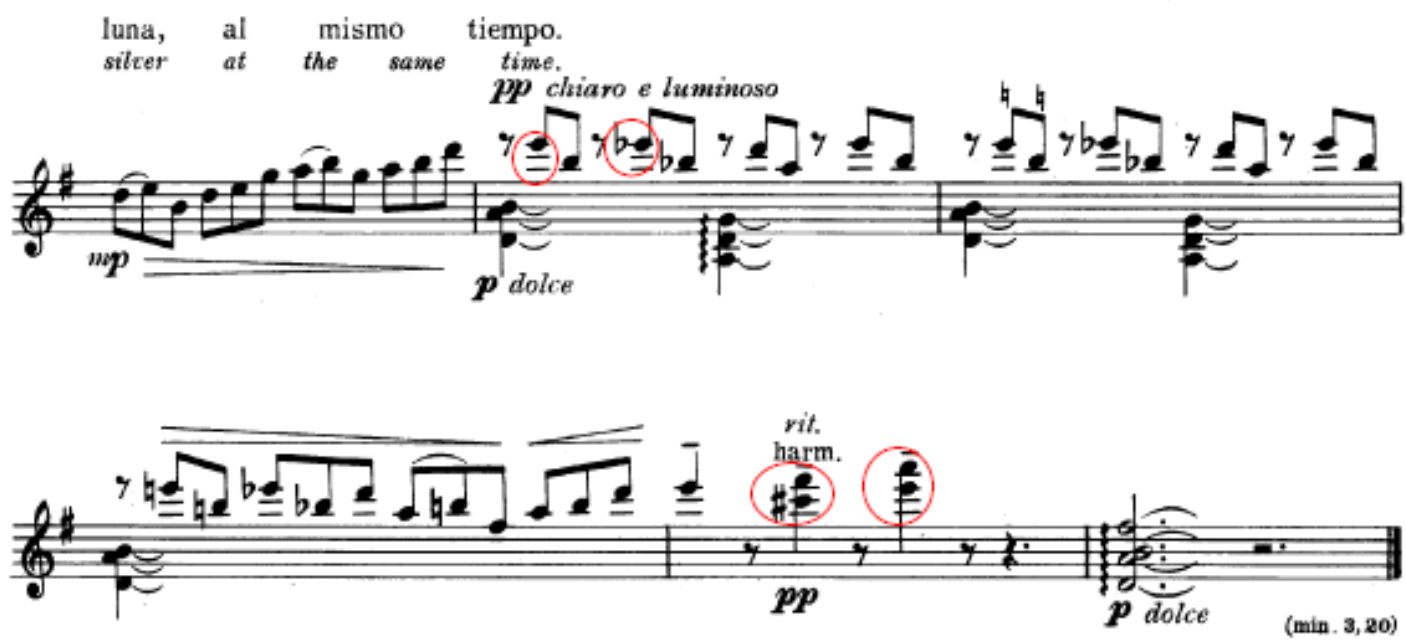

Fig. 13.

\section{CONCLUSIONES}

Después de haber desarrollado una primera aproximación a Juan Ramón Jiménez desde una perspectiva musical y, sobre todo, a las relaciones existentes entre el Platero y yo de Jiménez y Tedesco, podemos extraer algunas conclusiones.

Tras el análisis del primer movimiento podemos observar que el compositor utiliza las mismas pautas formales, ya que, por lo general, lo organiza en torno al texto, e incorpora cambios texturales y motívicos cada vez que se da una secuencia textual nueva.

También tenemos que plantear que Tedesco, además de musicalizar el texto de Juan Ramón Jiménez, realiza una selección de capítulos que le permiten desarrollar sus ideas compositivas, lo que le conduce a un enriquecimiento y reformulación del planteamiento pragmático de Juan Ramón Jiménez. Es decir, el compositor florentino introduce alturas en la voz de la narración cuando en el libro se proponen momentos más expresivos. Este es el caso del “Tiene asero” o la pregunta retórica “¿Platero?” del primer movimiento.

Lo anterior permite una mejora en la recepción del texto por parte del público y ayuda, por tanto, a la difusión de la obra juanrramoniana. Puede ser que Tedesco elija los capítulos que, bajo su criterio, le permiten potenciar mediante su música la expresividad de los mismos. Pone así "su grano de arena" que sirve para contribuir a la recepción del libro de Juan Ramón Jiménez, ayudando al oyente a sumergirse, más si cabe, en la obra.

Tendríamos también que resaltar que el Platero de Tedesco es una de las obras más extensas para guitarra, compuesta bajo iniciativa propia; es decir, no atiende en principio a ningún encargo, lo que concede al compositor libertad. Suponemos que, bajo la admiración del compositor a la cultura española, concretamente al libro Platero y yo, compone para guitarra esta pieza para que su amigo Andrés Segovia la interprete junto a un actor. Aunque 


\section{SiLVIA Nogales BARRIOS}

sepamos, gracias a fuentes como el musicólogo Gilardino o Corazón Otero, que la obra iba destinada a que Segovia la interpretase, no hemos encontrado indicios de que fuese un encargo del guitarrista. Además, conociendo brevemente la obra del compositor florentino, recordamos que entre 1960 y 1961 compuso dos grandes obras para guitarra, Los 24 Caprichos de Goya para guitarra sola (1961) y Platero y yo para narrador y guitarra (1960). Ambos comparten unas sonoridades cercanas y lenguaje parecido. Sí que se puede intuir una cierta evolución en Platero y yo -en cuanto a recursos armónicos y estéticos se refiere, unidos al original planteamiento de la conjunción de guitarra y narrador- si se compara con el Romancero Gitano de 1950 para coro y guitarra. Si bien, dicha evolución no es abrupta si comparamos, por ejemplo, el movimiento Procesión del Romancero con otros movimientos de Platero y yo.

Podemos expresar, por tanto, que Tedesco conserva su estilo, es fiel a su estética, lo que no quiere decir que, mientras en el contexto musical a nivel mundial encontramos a John Cage o a compositores que están componiendo obras seriales y refundando la retórica, esta música carezca de calidad o sea irrelevante. Además, si nos introducimos dentro del repertorio guitarrístico estamos ante una pieza extensa y de calidad, hasta el punto de que proporciona una evolución del instrumento. Hemos de decir que el libro Platero y yo encuentra en el repertorio guitarrístico distintas musicalizaciones como es el Platero y yo de Eduardo Sainz de la Maza, considerada esta última una obra importante del repertorio. Sin embargo, aunque es extensa y está orientada al poema sinfónico, no llega a la extensión de la de Tedesco. En las piezas de Sainz de la Maza se tiene en cuenta el texto se encabeza cada movimiento con algunas frases al comienzo del capítulo al que hace referencia, siendo en principio pensadas para que el intérprete encuentre el ambiente de cada movimiento- pero no está pensando para ser recitado. Estamos, por tanto, con el Platero de Tedesco, ante una de las pocas obras para narrador y guitarra en la que la conjunción entre el texto y la música se realiza de una forma sobresaliente y consciente por parte del compositor.

El Platero y yo del compositor florentino no puede más que enriquecer el repertorio y la interpretación guitarrística, ya que somete al intérprete a un doble reto: por un lado, el de ejecución, relacionado puramente con la técnica; por otro lado, la vertiente interpretativa, al tener que adaptarse a la figura del narrador. Éste último irá recitando el texto juanrramoniano que ha sido incorporado cuidadosamente por el compositor para que se realice una adecuada conjunción entre texto y música, como si una obra de cámara se tratase. La elección de la guitarra para Platero y yo por parte de Tedesco, como dijimos en el análisis del primer movimiento, no es aleatoria, sino que el carácter modal del instrumento, unido a su "sabor" español, casa perfectamente con la estética del libro. Además, la formación de voz y guitarra siempre ha sido de las más (si no la más) adecuadas para ambos instrumentos en la música de cámara, convirtiéndose en ideal para la difusión de esta obra.

\section{BIBLIOGRAFÍA}




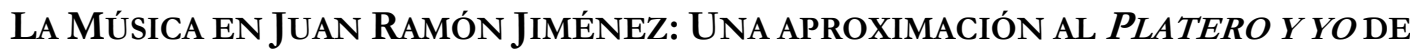 MARIO CASTELNUOVO-TEDESCO}

FUENTES PRIMARIAS

Castelnuovo-Tedesco, M. (1960). Platero y Yo: obra para narrador y guitarra. Milán: Berben (2002). Jiménez J.R (1926). Platero y yo. Madrid: Residencia de Estudiantes.

Jiménez, J. R. (1990). Ideolojía (Antonio Sánchez Romeralo). Barcelona: Anthropos.

Jiménez, J. R. (2007). La Soledad Sonora. Huelva: Visor Libros.

Jiménez, J. R. (2009). Españoles de tres mundos (1914-1940). Visor Libros.

Jiménez, J. R. (2012). Epistolario I y II. Madrid: Residencia de Estudiantes.

Jiménez, J. R. (2014). Vida. Días de mi vida (1º Ed.). Valencia: Pre-Textos.

Jiménez, J.R (1914). Platero y yo. Madrid: La Lectura.

Jiménez, J.R (1917). Platero y yo. Madrid: Casa Editorial Calleja.

\section{FUENTES SECUNDARIAS}

Adam, J. M. (1992). Les textes: types et prototypes. Récit, description, argumentation, explication et dialogue. París: Nathan.

Alonso, S. (Ed) (2002). Música y literatura. Estudios semiológicos. Madrid: Arco-Libros.

Alvar, M. (2006). Simbolismo e Impresionismo en el Primer Juan Ramón. Boletin de la Real Academia Española. Alicante: Biblioteca Virtual Miguel de Cervantes.

Azam, G. (1983). La Obra de Juan Ramón Jiménez: Madrid: Editorial Nacional.

Bernardo, G. (1971). La Ironía de Juan Ramón Jiménez: ¿orgullo o tristeza?. AIH. Actas IV. Universidad de Stanford.

Bernardo, G. (1973). La Poesía de Juan Ramón Jiménez: Obra en Marcha. Barcelona: Ariel.

Campoamor González, A. (1976). Vida y Poesía de Juan Ramón Jiménez. Madrid: Ediciones Sedmay.

Camprubí Aymar, Z. (2006). Diario 3 (1951-1956) (pp. 40, 60, 120, 125, 175, 334). Madrid: Alianza Tres-EDUPR.

Casares Rodicio, E (1983). Música española de la generación de la república. Fundación Juan March. 


\section{SILVIA NOGALES BARRIOS}

Castelnuovo-Tedesco, M. (1960). Platero y yo [Grabado por Nelson Brenes, narrador; Frank Koonce, Guitarra]. Platero y Yo: Elegía Andaluza. [CD]. Soundset Recordings.

Crespo, A. (1999). Juan Ramón Jiménez y la pintura. Salamanca: Ediciones Universidad de Salamanca.

Defeci, A. (2004). Significado y Comprensión en la Música. Revista de Filosofía, 31, pp. 71-88.

De Persia, J. (2003). En torno a lo español en la música del siglo XX. Granada: Diputación de Granada.

García, C. C., \& Baena, E. (1991). Juan Ramón Jiménez: poesía total y obra en marcha. En: IV Congreso de Literatura Española Contemporánea, 13-16 de noviembre de 1990, Universidad de Málaga. Madrid: Antrhopos.

Gicovate, B. (1971). La Ironía de Juan Ramón Jiménez: jorgullo o tristeza? AIH. Actas IV (1971): Universidad de Stanford.

Gicovate, B. (1973). La Poesía de Juan Ramón Jiménez: Obra en Marcha. Barcelona: Ariel.

Gilardino, A. (2018). Mario Castelnuovo-Tedesco. Un Fiorentino a Beverly Hills. Milán: Ediciones Curzi.

Gullón, R. (2006). El último Juan Ramón Jiménez: Así se fueron los ríos. Madrid: Huerga y Fierro Editores.

Helguera, L. I. (1993). "El poema en prosa y la música”. Vuelta. Recuperado de https://www.letraslibres.com/sites/default/files/files6/files/pdfs articulos/Vuelta$\underline{\text { Vol17 } 196 \text { 10VueltDis e.pdf }}$

Intxausti, A. (2014). "Juan Ramón Jiménez: Un siglo con Platero y yo", El País, 17-03-2014. Recuperado de http://cultura.elpais.com/cultura/2014/03/17/actualidad/1395057935 228193.html

Marichal, J. (1993). Una espléndida década. Cuadernos Hispanoamericanos, N514-515, 25-38.

Otero, C. (1987). Mario Castelnuovo Tedesco: su vida y obra para guitarra. México: Ediciones Musicales Yólotl.

Palau de Nemes, G. (1974). Vida y Obra de Juan Ramón Jiménez: Madrid: Gredos.

Regino Sainz de la Maza. (1979). A fondo: Entrevista a Regino Sainz de la Maza. [Entrevista en vídeo]. TVE: A Fondo.

Richard Arellano Paez (2012, Diciembre 16). Regino Sainz de la Maza, Entrevista. Fuente https://www.youtube.com/watch?v=MXcylKtDXYo

Cuadernos de Investigación Musical, 2018, junio, nº 4, págs. 54-79.

ISSN: 2530-6847

DOI: $\underline{\text { http://dx.doi.org/10.18239/invesmusic.v0i4.1816 }}$ 


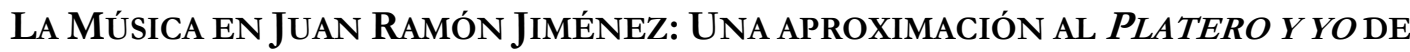 MaRio CASTELNUOVO-TEDESCO}

Sanz Manzano, M. A. (1999). La Música en el Universo Poético de Juan Ramón Jiménez. Tropelías: Revista de teoría de la literatura y literatura comparada, pp. 407-419.

Sopeña Ibañez, F. (1976). Manuel de Falla y el Mundo de la Cultura Española. Madrid: Gráficas Uguina.

Sopeña Ibañez, F. (1981). Juan Ramón Jiménez y Manuel de Falla. Los Cuadernos del Norte: Revista cultural de la Caja de Ahorros de Asturias, 2, pp. 54-57.

Fecha de recepción: 17/01/2018

Fecha de aceptación: 09/06/2018 